\title{
Prostatektomi Sonrası Gelişen Üretra Darlıkları
}

\author{
Fatih Hızlı, İsmail Selvi, Halil Başar
}

Onkoloji Eğitim ve Araştırma Hastanesi, Üroloji Kliniği, Ankara

$\dot{\bigcup}^{\bullet} \mathrm{r}$ retra darlıkları; tanısı, tedavi zorluğu, yüksek tekrarlama olasılığı, ameliyat sonrası hasta bakımı ve takibi açısından ürolojinin karmaşık konularından biridir. Etyolojisinde eksternal travma ve iyatrojenik nedenler ön plandadır. TUR-P sonrası üretra darlığı görülme oranı \%2.29.8 iken; açık prostatektomide bu oran \%1.9'dur (1-2). Daha önceki serilerde \%4-29 arasındaki darlık oranı, cerrahi enstrümanlardaki ve teknikteki gelişmelere bağlı olarak günümüzde önemli ölçüde azalmıştır (3-5). Üretra darlıkları en sık bulber üretrada gözlenmekle beraber, daha seyrek olarak penil üretrada da gelişebilmektedir.

TUR-P sonrası üretra darlığı gelişiminde etkili olabilecek bazı faktörler öne sürülmesine rağmen etiyolojisi halen tam olarak anlaşılamamıştır. Normal koşullarda prostatektomi'den hemen sonra mesane boynu ve membranöz üretradaki yara kenarları opere edilen prostatik üretrayı örtecek şekilde yeni mukozayı oluşturmakta ve operasyon sonrasindaki spontan miksiyon ile kan pihtıları, fibrin ve nekrotik hücre kümeleri vücuttan uzaklaştırılmaktadır. Ancak öne sürülen bir hipoteze göre, postoperatif dönemde uzun süre miksiyon meydana gelmezse, mesane boynu ve membranöz üretradaki yara kenarlarında kan pihtısı ve fibrin birikimi meydana gelmekte, bu durum da; fibrozis ve bunu takiben striktür oluşumuna yol açmaktadır (6). Nielsen ve Nordling subepitelyal boşluğa idrar ekstravazasyonunun ödem ve progresif inflamasyona yol açtığını ve böylece üretral stenoz ve striktür gelişimine neden olduğunu; sonrasında ise artmış intramural işeme basıncının mukozal bariyerdeki kaçağın artmasına neden olduğunu belirtmişlerdir (7). Pansadoro ve Emiliozzi ise; prostatik üretral darlıkların fizyopatolojisinde rol oynayan gecikmiş epitelizasyonunun, fibrotik dokunun aşırı büyümesi ile kombine olduğu durumlarda geliştiğini ileri sürmüştür (8).

Uretra darlıklarının tanısında çeşitli görüntüleme yöntemleri kullanılmaktadır. Retrograd üretrografi darlığın distalini gösterirken, idrar yaparken çekilen sistoüretrografi darlığın proksimal sınırlarını ortaya koyar. İkisi birlikte yapıldığında eşlik edebilecek fistül, yalancı yollar, mesane trabekülasyonu, vezikoüreteral reflü ve postmiksiyonel rezidüel idrar miktarını da gösterebilmektedir. Bu nedenle, bu iki inceleme her zaman birlikte yapılmalıdır. Ayrıca anterioroblik görüntü üretranın tam boyunu en iyi şekilde gösterir.

Diğer taraftan ultrasonografi (US) de üretra darlığını ve uygun bir donanımla onu çevreleyen korpus spongiosumdaki fibrozisin derecesini gösterebilir (9). Yine de, çoğu ürolog US'yi yararlı bir tanı yöntemi olarak kabul etmemektedir. Ancak intraluminal US teknolojisi ilerleyip yaygın şekilde kullanılabildiğinde bu durum değişebilir.

Üretra darlığ1 gelişiminde sorumlu tutulan nedenler arasında; büyük prostat hacmi ve buna bağlı uzun operasyon süresi, kullanılan kateterin büyüklüğü, idrarın enfekte olması, kalın rezektoskop ve yüksek enerji kullanımı, fazla giriş-çıkış yapılması ve şaftta oluşan enerji kaçakları ile üretra mukozasının hasarlanması bulunmaktadır $(4,5)$.

Hızlı ve ark.ları'nın yaptığı bir çalışmada ise; hasta yaşının, ameliyat sonrası üretra darlığı gelişiminde önemli bir risk faktörü olduğu; uzun rezeksiyon süresi bulunan hastalarda postoperatif dönemde oluşan üretral darlık uzunluğunun ve internal üretrotomi ihtiyacını artırdığı; kullanılan sonda çapı ile üretral darlık uzunluğu arasında herhangi bir ilişki bulunmamasına karşın, sonda kalış süresi uzun olan hastalarda internal üretrotomi sayısının ve üretral darlık uzunluğunun istatistiksel olarak anlamlı şekilde arttığı saptanmıştır (10). Ameliyat öncesi veya sonrası enfeksiyon varl1ğının darlık riskini artırdığı bazı kaynaklarda bildirilmişse de $(11,12)$, bu çalışmada, ameliyat öncesi ve sonrası enfeksiyonu olan hastaların sayıca birbirine yakın olması nedeni ile benzer risk artışı bulunamamıştır (10). Bu çalışmada tedavi yöntemi olarak internal üretrotomi uygulanmış olup istenmeyen yan etkiler, sıklık sırasına göre kanama, epididimorşit, ateş ve yalancı yol olarak saptanmıştır ve tüm olgular incelendiğinde \%84 gibi yüksek başarılı sonuçlar elde edilmiştir (10).

Operasyon öncesinde üretra çapının dar olmasının postoperatif dönemde darlık gelişme riskini arttırdığını ve bu nedenle TUR-P öncesi üretrotom ile internal üretrotomi yapılmasının faydalı olduğunu savunan görüşler de bulunmaktadir $(13,14)$.

Mesane boynunun gereğinden fazla rezeksiyonundan kaçınılması, cihazların periyodik bakımlarının yapılması, kullanılan şafttaki olası kaçak noktalarının erken tespit edilmesi ve yeterli miktarda kayganlaştırıcı madde kullanılması ile uretral darlıktan kaçınılması mümkündür.

Hafif derecedeki darlıkların tedavisinde yumuşak dilatasyon denenebilir. Bu teknik Nelaton, Tiemann uçlu veya klasik Foley sondalarla yapılır. Bu yöntemde mesaneye geçirilebilen en inceden başlanarak sirayla daha kalın sondalar yerleştirilir. Bu işleme 20-22 F kalibrasyona kadar devam edilir. Yumuşak dilatasyon hekim tarafından uygulanabileceği gibi hastaların kendisi de yapabilir.

Rijid dilatasyon ise; daha sert yapıda olan Hegar, Benique gibi bujilerle yapılmaktadır. Bu yöntem hastane şartlarında hekim tarafınca uygulanmaktadır. Yumuşak dilatasyonda olduğu gibi giderek kalınlaşan bujilerin sırayla mesaneye geçirilmesi ile yapılır. Fakat bu yöntem kör bir yöntemdir 
bu yüzden basit bir darlığı kompleks darlıklara çevirebilir, üretral travmalara ve yalancı yol (false route) oluşumuna yol açabilir. Tek bir üretral dilatasyonun 4 yil sonunda halen başarılı olma oranı yaklaşık olarak \%20 olarak bildirilmiştir $(8,15)$. Kronik dilatasyon ise yanlış yol, kanama, üriner sistem enfeksiyonu, septisemi ve en sonunda geçilemeyen darlık oluşumuna neden olabilmektedir (16).

İnternal üretrotomi genellikle 2-3 cm'den kısa darlıklarda uygulanmaktadır. Sıfır derece $\left(0^{\circ}\right)$ optik bulunan üretroskop ile girilerek, soğuk biçak ile saat 12 hizasından kesi yapılarak dar segment açılır. Bazen ileri derecede daralma gözlenen olgularda işlemi güvenle gerçekleştirebilmek için önce darlık içerisinden kılavuz tel gönderilir ve daha sonra bu tel üzerinden üretrotomi işlemi uygulanır. İşlem sonrasında yerleştirilen Foley sonda 7-14 gün arasında tutulur ve bunun üzerinden iyileşme gerçekleşir. Üretrotomi veya dilatasyon ile genelde kısa, keskin, tek bir bulber darlık tamamen iyileştirilebilir. Penil üretradaki darlıklarda, uzun darlıklarda ve belirgin periüretral fibrozis olan olgularda üretrotomi ile başarı oranı daha düşüktür (17).

Darlıkların yaklaşık \%60'1 tedaviden sonraki bir yıl içerisinde tekrarlamaktadır. Steenkamp ve ark.'ları yaptıkları prospektif çalışmada, rekürrense kadar geçen sürenin major prognostik faktör olduğunu göstermiştir (15). İlk üretrotomiden sonra yapılacak herhangi bir üretrotomi veya üretral dilatasyon büyük bir olasılıkla palyatif amaçlı olacaktır (16). Düzenli üretral dilatasyon düşünülen, özellikle yaşlı, genel sağlık durumu operasyon için uygun olmayan veya ameliyat olmayı istemeyen hastalarda sabahları $14 \mathrm{~F}$ veya $16 \mathrm{~F}^{\prime}$ lik bir sonda ile yapılan temiz aralıklı kateterizasyon uygun bir alternatiftir. Bulber üretrada yüzeysel ama semptomatik darlığı bulunan yaşlı hastalardan seçilmiş bazı vakalarda intraluminal stent yararlı olabilir. Ancak fibrozisin tekrarlama ve üretrayı yeniden tıkama eğiliminde olmasından dolayı gençlerde veya büyük fibrotik darlığı olan hastalarda intraluminal stentler kullanılmamalıdır.

Üretral stentlerle ilgili uzun takip gerektiren çalışmalar migrasyon, enkrustasyon, enfeksiyon, ağrı ve tekrar girişim gibi komplikasyonları ortaya koymuştur. Takip süreleri 11 yıla kadar varan çalışmalarda bulber darlık tanısıyla üretral stent yerleştirilen hastalarda tekrar girişim oranı \%33-45 oranında saptanmıstır (18). Yine bazı çalışmalarda prostat kanseri tedavisi nedeniyle posterior üretral darlık gelişen ve UroLume ${ }^{\circledR}$ stent yerleştirilen hastalarda tekrar girişim oranı \%11-40 oranında saptanmıştır (19). Bu komplikasyonlar ve yüksek tekrar girişim oranları nedeniyle üretral stentler iyi seçilmiş hastalarda primer tedavi modaliteleri yerine uygulanabilecek bir yöntem olarak değerlendirilmeye başlanmıştır (20). Üretral stentler her ne kadar cerrahiye uygun olmayan hastalarda kalıcı kateterlere bir alternatif olabileceği düşünülse de; kalıcı kateterlerin tersine işlevsel bir detrusor gerektirmektedir $(20,21)$. İlk kullanilan metalik stentlerin enkrustasyon, pozisyon kaybı ve sık enfeksiyon gibi dezavantajları var iken, ilerleyen yıllarda Milroy ve Allen tarafından üzerinde epitelizasyona izin veren yani idrarla direk temas etmeyen ve dokuya daha sıkı tutunan, daha geniş lümene sahip Urolume $^{\circledR}$ stentler geliştirilmistir $(22,23)$. Üretral stent yerlestirilmesi sonrası oluşabilecek komplikasyonlardan belki de en önemlilerinden birisi re-stenozistir. Bu komplikasyonun tedavisi konusunda henüz bir fikir birliği sağlanamamıstır. Fakat bu konuda oluşan genel kanı re-stenoz tedavi şeklinin darlık segmentinin uzunluğu ile bağlantılı olması gerekliliği- dir. Stent sonrası tekrar gelişen darlıklarda genellikle öncelikle endoskopik girişimler, endoskopinin başarısız olduğu durumlarda ise hastalara üretroplasti gerekebileceği bildirilmektedir (24).

Üretrotomi veya dilatasyon sonrasında darlıkları yineleyen hastalarda ise uygulanacak tek olasılık üretroplasti gibi gözükmektedir (25). Yine de literatürde, travmatik üretra darlıklarında başarı ile uygulanan uç-uca anastomotik üretroplasti ve yerine koyma (substitusyon) üretroplastisi (Barbagli işlemi, Orandi işlemi) gibi operasyonların prostatektomi sonrasında gelişen üretra darlıklarında kullanımı ile ilgili araştırma yok denecek kadar azdır (26). Lumen ve Oosterlinck'in sınırlı sayıda hasta içeren çalışmalarında TUR-P/açık prostatektomi sonrası gelişen üretra darlıklarında uygulanan uç uca anastomoz ile yapılan üretroplastiden sonra yüz güldürücü sonuçlar alınmıştır (27). Bu uygulama ile ilgili olarak daha çok hasta içeren çalışmalara ihtiyaç duyulmaktadır (6).

Kullanılabilecek bir diğer tedavi yöntemi de lazer üretrotomidir. Son 30 yıl boyunca anterior üretra darlıklarında insizyon, rezeksiyon ve vaporizasyon amaçlı farklı dalga boyları denenmiştir. Başlangıçta argon, excimer, ve diyot lazerler denenmiş sonrasında düşük güç potasyum titanylfosfat (KTP) ve kontak tip neodymium: yttrium-aluminumgarnet laserler (Nd: YAG) kullanılmıştır. Son 10 yıl içerisinde ise holmium and thulium lazerler eklenmiştir. Kısa dönem gözleme dayalı çalışmalarda, lazer üretrotominin internal üretrotomiye ek bir üstünlügü saptanamamış olup rutin kullanımı henüz önerilmemektedir (28).

İnternal üretrotominin başarısını arttırmak için sistemik veya lokal olarak çeşitli maddeler kullanılmıştır (29). Hebert tarafından önerilen transüretral triamsinolon enjeksiyonu dışında sistemik steroid uygulaması veya triamsinolonlu merhem kullanımıda denenmiştir (30). Hosseini ve ark.ları tarafından yapılan çalışmada, internal üretrotomi sonrasında 6 ay süreyle triamsinolonlu merhemle yapılan temiz aralıklı kateterizasyon grubu ile su bazlı kayganlaştırıcı kullanılan grup karşılaştırılmış ve 12 aylık takip sonrasında üretral darlık gelişme oranı triamsinolon grubunda bir miktar daha az tespit edilmesine karşın istatistiksel bir fark saptanamamıştır (31).

Sonuç olarak, TUR esnasında üretra darlığı gelişme riskini azaltmak amacıyla travmatik etkisi olan rezeksiyon ve ameliyat sonrası sonda kalış süresinin mümkün olduğu kadar kısa tutulması gerekir. Özellikle yaşlı hastalara, TUR sonrası darlık gelişme riskinin daha fazla olduğu, darlık gelişmiş hastalara ise; artan darlık uzunluğunun tekrarlayan darlık riskini artırabileceği anlatılmalıdır. Diğer taraftan, internal üretrotomi, kolay bir yöntem olması, istenmeyen yan etkilerin az olması, daha az nekroz gelişmesi, lokal anestezi ile de uygulanabilmesi ve nüks halinde tekrar kullanılabilmesi nedeni ile üretra darlığı tedavisinde ilk başvurulacak yöntem olarak varlığını devam ettirmektedir (10).

\section{Kaynaklar}

1. Rassweiler J, Teber D, Kuntz R, Hofmann R. Complications of transurethral resection of prostate (TURP) -incidence, management and prevention. Eur Urol 2006, 50: 969-979.

2. Varkarakis I, Kyriakakis Z, Delis A, et al. Long-term results of open transvesical. Prostatectomy from a contemporary series of patients. Urology 2004; 64: 306-10. 
3. Nielsen KK, Nordling J. Urethral stricture following transurethral prostatectomy. Urology 1990; 34: 18-24.

4. Hammarsten J, Lindqvist K, Sunzel H. Urethral strictures following transurethral resection of the prostate: the role of the catheter. BJU Int 1989; 63: 397-400.

5. Hart AJL, Fowler JW. Incidence of urethral strictures following transurethral prostatectomy: review of 2223 resections. J Urol 1997; 117: 194-201.

6. Lumen N, Oosterlinck W. Challenging nontraumatic posterior urethral strictures treated with urethroplasty: A preliminary report. Int Braz J Urol 2009; 35: 442-449.

7. Lentz HC, Mebust WK, Foret JD. Urethral strictures following transurethral prostatectomy. J Urol 1977; 117: 194-197.

8. Pansadoro V, Emiliozzi P. Iatrogenic prostatic urethral strictures: classification and endoscopic treatment. Urology 1999; 53: 784-789.

9. Morey AF, McAninch JW. Role of preoperative sonourethrography in bulbar urethral reconstruction. J Urol 1997; 158: 1376-1379.

10. Hızlı F, Berkmen F, Güneş M.N, Yürür H, Transüretral rezeksiyon sonrası gelişen üretra darlıklarında internal üretrotomi sonuçları ve literatürün gözden geçirilmesi. Türk Üroloji Dergisi 2005; 31: 417-422.

11. Murdoch DA, Badenoch DF: Oral ciprofloxacin as prophylaxis for optical urethrotomy. Br J Urol 60: 352354, 1987.

12. Pain JA, Collier JDG: Factors influencing recurrence of urethral strictures after endoscopic urethrotomy: The role of infection and perioperative antibiotics: Br J Urol 1984; 56: 217-219.

13. Bailey MJ, Shearer RJ. The role of internal urethrotomy in the prevention of urethral Strictures following transurethral resection of the prostate. Br J Urol 1979; 51: 28-31.

14. Ala Opas MY, Aitola PT, Metsola EJ. Evaluation of immediate and late results of transurethral resection of the prostate. Scand J Urol Nephrol 1993; 27: 235-239.

15. Steenkamp JW, Heyns CF, De Kock MLS. Internal urethrotomy versus dilation as Treatment for male urethral strictures: a prospective, randomized comparison. J Urol 1997; 157: 98-101.

16. Oosterlinck W. Treatment of bulbar urethral strictures: a review, with personal critical remarks. ScientificWorldJournal, 2003, 3: 443-454.

17. Pansadoro V, Emiliozzi P. Internal urethrotomy in the management of anterior. Urethral strictures: long-term follow-up. J Urol 1996; 156: 73-75.

18. Beier-Holgersen R, Brasso K, Nordling J, Andersen JT. The "Wallstent": a new stent for the treatment of urethral strictures. Scand J Urol Nephrol 1993; 27: 247-250.
19. De Vocht TF, van Venrooij GE, Boon TA. Self-expanding stent insertion for urethral strictures: a 10-year follow-up. BJU Int 2003; 91: 627-630.

20. Hussain M, Greenwell TJ, Shah J, Mundy A. Longtermresults of a self-expanding wallstent in the treatment of urethral stricture. BJU Int. 2004;94:1037-1039.

21. Chapple CR, Bhargava S. Management of the failure of a permanently implanted urethral stent - a therapeutic challenge. Eur Urol. 2008; 54:665-670.

22. Palminteri E, Gacci M, Berdondini E, et al. Management of urethral stent failure for recurrent anterior urethral strictures. Eur Urol. 2010; 57:615-621.

23. Palminteri E. Stents and urethral strictures: a lesson learned ? Eur Urol. 2008; 54:498-500.

24. Jordan G, van der Burght M. Memokath_044 - a removable stent for treatment of recurrent bulbar urethral strictures. Results of the North American study group's multi-centre trial [abstract\#1103324]. Presented at the 26th Congress of the European Association of Urology; Mar 18-22, 2011; Vienna, Austria.

25. Breyer BN, McAninch JW, Whitson JM, et al. Multivariate analysis of risk factors for long-term urethroplasty outcome. J Urol 2010; 183:613-617.

26. Roehrborn CG, McConnell JD. Analysis of factors contributing to success or failure of 1-stage urethroplasty for urethral stricture disease. J Urol 1994;151:869-874.

27. Barbagli G, Palminteri E, Lazzeri M, et al. Long-term outcome of urethroplasty after failed urethrotomy versus primary repair. J Urol 2001; 165(6 Pt 1):1918-1919.

28.Jill C. Buckley, ChrisHeyns, Peter Gilling, and Jeff Carney SIU/ICUD Consultation on Urethral Strictures: Dilation, Internal Urethrotomy, and Stenting of Male Anterior Urethral Strictures. Urology 2014; 83: 18-22

29. Mundy AR. Adjuncts to visual internal urethrotomy to reduce the recurrence rate of anterior urethral strictures. Eur Urol 2007; 51: 1467-1468.

30. Hebert PW. The treatment of urethral stricture: transurethral injection of triamcinolone. J Urol, 1972 108: 745-747.

31. Hosseini J, Kaviani A, Golshan AR. Clean intermittent catheterization with triamcinolone ointment following internal urethrotomy. Urol J 2008; 5: 265-268.

Yazışma Adresi:

Fatih Hizlı,

Onkoloji Ĕ̆itim ve Araştırma Hastanesi, Üroloji Kliniği,

Demetevler, 06530, Ankara

Tel: +905324734441

Fax: +903123454979

e-mail: fatihhizli33@yahoo.com 